\title{
A qualitative study about palliative care patients' experiences of comfort: Implications for nursing diagnosis and interventions
}

\author{
Sara Pinto ${ }^{* 1,2}$, Sílvia Caldeira ${ }^{3}$, José Carlos Martins ${ }^{4,5}$ \\ ${ }^{1}$ Instituto de Ciências Biomédicas Abel Salazar, University of Porto, Porto, Portugal \\ ${ }^{2}$ Centro Hospitalar São João, Porto, Portugal \\ ${ }^{3}$ Universidade Católica Portuguesa - Instituto de Ciências da Saúde - Lisboa, Portugal \\ ${ }^{4}$ Medical-Surgical Unit, Escola Superior de Enfermagem de Coimbra, Portugal \\ ${ }^{5}$ Department of Human Sciences and Health, Faculdade de Medicina da Universidade do Porto, Porto, Portugal
}

Received: November 30, 2016

Accepted: February 27, 2017

Online Published: March 7, 2017

DOI: $10.5430 /$ jnep.v7n8p37

URL: https://doi.org/10.5430/jnep.v7n8p37

\begin{abstract}
Background and objective: Comfort is a complex experience, particularly important to palliative care patients. Although it is listed in nursing classifications and taxonomies there is a gap between theory and practice. Thus, little research has been done about patient's perceptions and experiences in this context of care. This paper aims to analyze palliative care patients' experiences about comfort.

Methods: Qualitative study with fifteen participants, using in-depth, semi-structured, face-to-face interviews, tape-recorded, transcribed verbatim and analyzed using interpretative content analysis.

Results: Five main themes have been identified. Holistic comfort may be a difficult outcome for many end-of-life patients but the context of provision of care, the presence of family, the way information is managed, the search for meaning in life, and the need to keep life under control were perceived as important determinants for comfort.

Conclusions: This study provides a general overview about comfort experiences and the main discomforts of hospitalized patients who are suffering from chronic and incurable diseases. Findings highlight comfort as a complex intervention within multidisciplinary palliative care team and this is supporting the nursing diagnosis "Impaired Comfort" as a syndrome. The study adds a contribution to the accuracy and completeness of nursing classifications and nursing practice in palliative care.
\end{abstract}

Key Words: Comfort, Holistic health, Interview, Qualitative research, Palliative care

\section{INTRODUCTION}

Comfort is a critical goal of Palliative Care (PC) ${ }^{[1,2]}$ which aims to provide patients and family the highest quality of life, through the prevention and relief of suffering in all human life dimensions. ${ }^{[3]}$ Previous research has defined the concept of comfort as holistic, subjective, dynamic and a positive experience based on the satisfaction of the individual needs in one or more dimensions (physical, psychological, social, spiritual, environmental), which may result in physical relief and/or transcendence. ${ }^{[4,5]}$ Relief is related to the satisfaction of the most basic needs, ease with the feeling of calm and quiet (basilar to functional and efficient performance), and

\footnotetext{
* Correspondence: Sara Pinto; Email: sara.o.pinto@gmail.com; Address: Centro Hospitalar de São João, Serviço de Angiologia e Cirurgia Vascular. Alameda Prof. Hernâni Monteiro, 4200-319 Porto, Portugal.
} 
transcendence is related to the needs of self-control regarding decisions, life, future, and the transcendent. ${ }^{[4]}$

Despite all the knowledge development, theories and research about comfort and comforting, the concept is often considered complex ${ }^{[5-8]}$ and not easy to implement and evaluate in the clinical practice. ${ }^{[9-11]}$ First, comforting is a broad intervention comprising several activities, performed by different persons, and comprises patients and environmental factors. ${ }^{[6,10]}$ Secondly, nursing classifications and taxonomies are important instruments of nursing knowledge, but miss clarity and consistency on this topic. For example, the International Classification for Nursing Practice $(R)$ (ICNP $₫$ ) provides a reductionist definition of comfort, only in its physical dimension. ${ }^{[12]}$ The taxonomy II of NANDA International (NANDA-I) includes a domain "Comfort", and the diagnosis labeled as "Impaired Comfort" (00214) is listed in the three classes. ${ }^{[13]}$ But, in the taxonomy III, this domain does not exist and can be found as a class of a new domain entitled "Existential". Additionally, a change of the diagnosis "Impaired Comfort" (00214) has been proposed, from a problem-focused diagnosis to a syndrome diagnosis. ${ }^{[14]}$ Comfort seems to be a complex experience integrating several diagnosis. ${ }^{[10]}$ Studies regarding patient's experiences can add an important contribution to modelling diagnosis, processes and outcomes, as well as to minimize the theorypractice gap that is often described.

Few studies have directly addressed PC patients' experiences of comfort during their illness journey, particularly in noncancer patients. ${ }^{[15]}$ Patients' perspectives are crucial in the understanding of the phenomena ${ }^{[16,17]}$ towards an accurate nursing diagnosis, which is defined as the clinical judgment towards patients' responses. ${ }^{[13]}$ The better the nurses may know the patients' perspectives, feelings and views, probably the better their needs will be addressed. ${ }^{[18-20]}$ Research based on patients' perspective could be critical to the diagnosis accuracy and to promote and implement effective interventions in PC.

This study aims to a) analyze PC patients' experiences about comfort, in order to operationalize the complex intervention "comforting" and b) contribute to the development of the nursing diagnosis "Impaired Comfort" from NANDA International.

\section{Methods}

Qualitative study using semi-structured and face-to-face interviews, tape-recorded, transcribed verbatim and analyzed using interpretative content analysis. The consolidated criteria for reporting qualitative research (COREQ) guidelines ${ }^{[21]}$ were used to guide all research procedures. These guidelines consist of a 32-item checklist, which helps researchers to describe their research, to improve rigor and quality of qualitative studies. The COREQ guidelines are organized in three domains. Domain 1 is related with personal characteristics of the research team and their relationship with participants; domain 2 concerns the study design; and domain 3 concerns the analysis of the findings. ${ }^{[21]}$ Specific information regarding the methodological approach are provided in the following sub-headings.

\subsection{Participants and recruitment}

Participants were purposively recruited at five in-patient medical-surgical settings from an acute and central hospital in the north of Portugal (medicine, general surgery, neurosurgery, pneumology and vascular surgery). Acute settings were chosen because in Portugal the vast majority of patients with PC needs remain in acute settings, due to the shortage of beds in PC units.

Fifteen in-patients, aged over 18 years, with a i) diagnosed chronic, incurable and progressive disease and ii) followed by the in-hospital PC team were recruited (see Table 1). The inclusion criteria were iii) impaired comfort: participants that have recently had (or were still experiencing) uncomfortable experiences, such as agonizing pain, traumatic injuries, breathlessness, nausea, loneliness or spiritual distress. The inclusion criteria were referred from nurses and validated by a retrospective chart review of patient's records on the last seven days. Exclusion criteria were: i) cognitive impairment reported in the clinical records and by nurses, ii) lack of capacity to give informed consent, and iii) not fluent in Portuguese. Interviews were conducted between January and April 2015, until data saturation. To enhance the rigor and quality of data collection and findings analysis, data was collected in different five in-patient medical-surgical settings (space triangulation).

\subsection{Interview procedure}

Four patients had moving limitations and the interviews took place in their unit. The remaining eleven interviews were held in a meeting room. The principal researcher conducted the fifteen in-depth, semi-structured and face-to-face interviews (SP, female, nurse and master's degree in PC). One participant asked for her daughter to be present during the interview, which was allowed. The interviewer also took field notes (particularly non-verbal language). The interview was structured and based on two questions: Please focus on your illness journey, at home or in hospital, and (1) Please describe an episode when you felt comfortable? (2) Please describe an episode when you felt uncomfortable? Socio-demographic and clinical data were collected in the beginning, before the 
audio-recording, in order to preserve confidentiality. The interviews ranged from 35 to 59 minutes (median interview length was $45 \mathrm{~min}$ ).

\subsection{Data analysis}

The data were analyzed using deductive content analysis, which comprises coding, organizing and classifying data by principal themes, concepts, categories and abstraction. ${ }^{[22]}$ The deductive content analysis was based on the Theory of Comfort proposed by Kolcaba, in which the author states that comfort can occur in four contexts: physical, psycho- spiritual, social and environmental. ${ }^{[4]}$

In a first phase, the interviews were transcribed verbatim, read twice, organized in descriptive coding by the principal researcher (SP) and then data were organized into emerging categories. In a second phase, data were independently analyzed, coded and organized by another researcher (SC). Findings were then discussed and, whenever necessary, revisited, recoded and re-categorized by the three researchers (SP, SC and JCM). The NVivo 8 Program was used (devised by QSR international in 2008).

Table 1. Participants demographic and health data

\begin{tabular}{|c|c|}
\hline Items & $\mathbf{n}$ \\
\hline \multicolumn{2}{|l|}{ Gender } \\
\hline Male & 10 \\
\hline Female & 5 \\
\hline Age (years) (range: min-max) & Range 71.27 (36-78) \\
\hline \multicolumn{2}{|l|}{ Civil Status } \\
\hline Single & 1 \\
\hline Married & 12 \\
\hline Widow & 1 \\
\hline Divorced & 1 \\
\hline \multicolumn{2}{|l|}{ Educational Degree } \\
\hline Primary education (4 years) & 12 \\
\hline Professional Course & 1 \\
\hline Graduated & 2 \\
\hline \multicolumn{2}{|l|}{ Professional Situation } \\
\hline Work absence due to illness & 7 \\
\hline Unemployed & 1 \\
\hline Retired & 7 \\
\hline \multicolumn{2}{|l|}{ Diagnoses } \\
\hline Brain Tumor (Glioblastoma Multiforme) & 3 \\
\hline Lung Tumor & 4 \\
\hline Pancreatic Cancer & 2 \\
\hline End-Stage Renal Disease & 1 \\
\hline Chronic Heart Failure (NYHA III, NYHA IV)* & 2 \\
\hline Chronic Obstructive Pulmonary Disease (GOLD III)** & 2 \\
\hline Chronic Occlusive Arterial Disease of the Extremities & 1 \\
\hline Hospitalization Time & Range 33.5 days (10-68) \\
\hline \multicolumn{2}{|c|}{ Agonizing Symptoms reported in Nursing Records (last 7 days) } \\
\hline Pain & 8 \\
\hline Breathlessness & 6 \\
\hline Anxiety & 5 \\
\hline Difficulty in Resting & 5 \\
\hline Nausea & 4 \\
\hline Vomits & 1 \\
\hline Constipation & 4 \\
\hline Spiritual Distress & 1 \\
\hline
\end{tabular}

*NYHA: New York Heart Association, **GOLD: Global Initiative for Chronic Obstructive Lung Disease. 


\subsection{Ethical considerations}

The research was approved by the institutional ethics committee (CHSJ, CES 191-14, 20 November 2014). Participants were given written and verbal information of the study's purpose, their voluntary participation and confidentiality, and the informed consent was obtained. Nurses who collaborate were also asked if they freely agreed to participate.

\section{Results}

\subsection{Participants}

The majority of participants was married, had completed primary education (4 years), and was retired or on sick leave.
All had a diagnosed chronic, incurable and progressive disease at an advanced stage (brain tumor, lung tumor, pancreatic cancer, end-stage renal disease, chronic heart failure or chronic obstructive pulmonary disease) (see Table 1).

\subsection{Emerged Themes}

Participants' comfort experiences were organized in five main themes: 1) Me and what I feel; 2) Me and I how I react; 3) Me a human being in society; 4) Me and the meaning of my life; 5) Me and the world around me (see Figure 1).

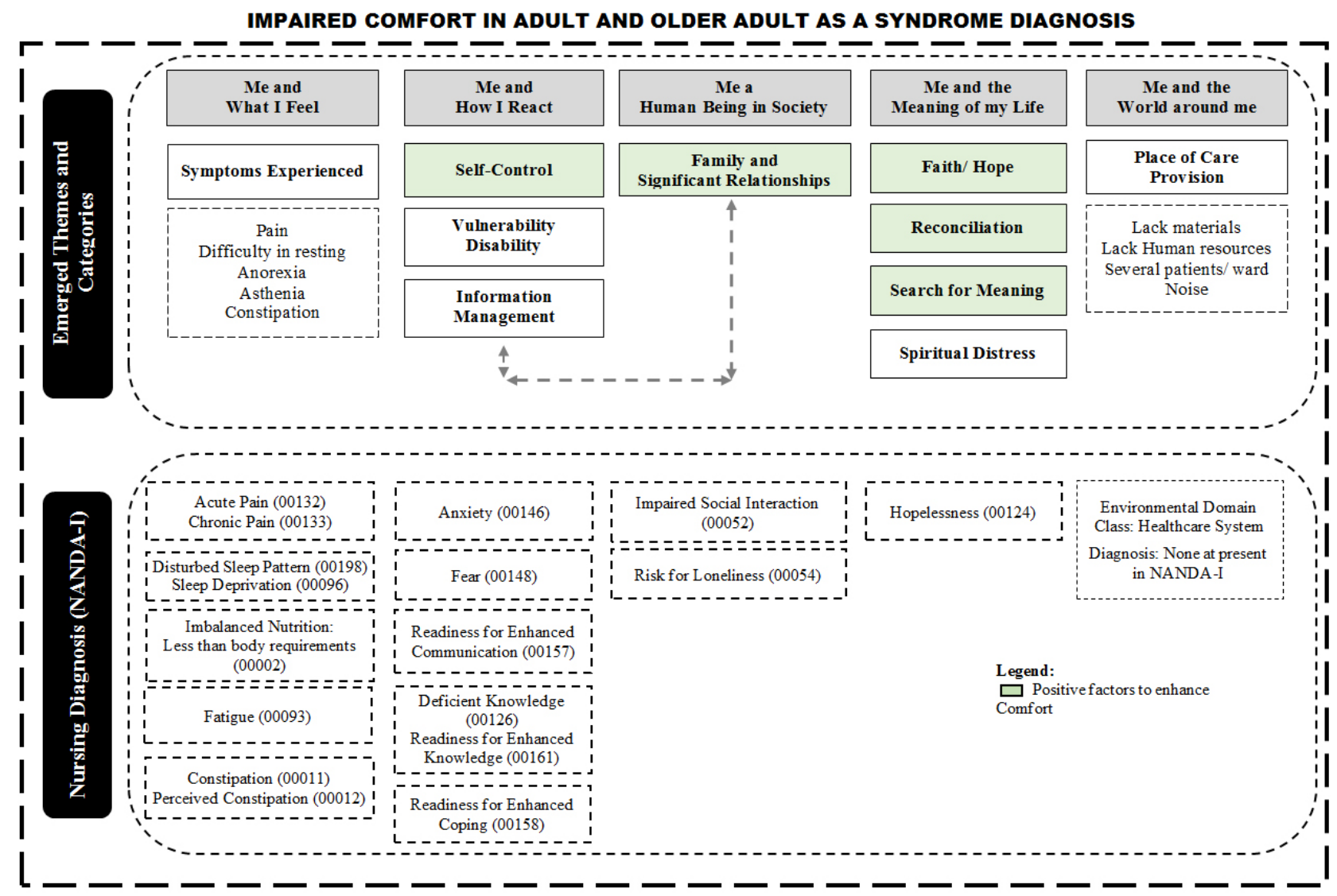

Figure 1. Impaired Comfort as a Syndrome Diagnosis: Themes, Categories and Nursing Diagnosis (Defining Characteristics)

\subsubsection{Me and what I feel}

The main uncomfortable symptoms reported by patients were pain, difficulty in resting, anorexia, asthenia and constipation. Pain and difficulty in resting were those with a greatest impact on patients' comfort. "I cannot" and "I do not feel well" are the most frequent expressions. As described by some patients, pain is an uncomfortable experience, which jeopardizes other activities:

"With pain I can't do anything." (P15)
Resting periods are considered insufficient and sporadic, particularly in hospital, not only because of pain and other clinical conditions (e.g. nausea or breathless), but also due to healthcare routines (medication, for example) or due to the presence of other patients in the wards. Besides this difficulty in falling asleep, participants state they can't sleep like before:

"It is not easy to rest here. Since I've been here, I still haven't sleep an entire night ..." (P11) 


\subsubsection{Me and how I react}

This theme addresses three categories: self-control, vulnerability and disability and information management.

Self-control The lack of security and balance were mentioned as factors that interfere with self-control and coping with the disease:

“(... ) I'm not well balanced. I don't know what to do with my life. I do not feel safe. And I don't know what will happen next.'(P2)

Vulnerability and disability Physical dependence is a condition that affects patients' comfort and promotes a sense of vulnerability:

"The feeling of being vulnerable and dependent is terrible. [...] Situations as simple as going to the toilet or being constipated and needing help... [pause] I'd rather not say anything than have to speak on this subject." (P12)

Information Management This category concerns the ability to obtain and understand health-related knowledge or messages and how this process can help patients' decision making. Physicians were seen as providing little and unclear information. For this reason the presence of the family during these conversations seems crucial:

"I think they [the doctors] should tell us ... the best path to follow. (...) Because we need orientation and they are here for that! (...) They have more experience... [pause] They should help us." (P13)

\subsubsection{Me a human being in society}

This topic highlights the importance of family and significant relationships. The presence, attention, affection and support provided by family and relatives are seen as key-elements for achieving comfort. To love and to be loved is essential for coping with the discomfort imposed by disease and hospitalization. It is, also, a rescue from loneliness, allowing the patient to feel alive, feel like a person and not just a number or a disease, such as expressed by a patient:

"Friends who came to visit and who I was not expecting, or who send me messages ... (...) Feeling in an unimaginable way the love, the affection, the care of the people closest to me is still something that touched me very much." (P7)

Gratitude towards the healthcare team, family and friends was also highlighted in patients' comments:

Published by Sciedu Press
“(...) I would like to do something to show them how they made me feel so great, I felt really loved ..." (P7)

\subsubsection{Me and the meaning of my life}

Patient narratives showed that disease and the end of life leads people to question the meaning and purpose of their lives. Faith and hope, reconciliation, meaning of life and spiritual distress were the categories of this topic.

Faith and hope Faith was considered as a coping strategy decisive for comfort experience:

"I am in a difficult situation and have to resort

to my faith in order to calm myself." (P14)

Hope is strictly associated with faith, and was described as a paradox. Participants stated that is important to keep believing in a solution or miracle. However, the attitudes and behavior of medical staff is, sometimes, inconsistent. Participants reported that their body language does not always correspond to their words. This inconsistency creates fear, uncertainty and hopelessness, which are negative factors on patients' comfort:

"Sometimes they say one thing but their faces... their faces say another. And I realize that there is something wrong." (P8)

Reconciliation Reconciliation is the resolution of personal or interpersonal conflicts perceived by patients, and concerns the need of forgiveness and the feelings of guilt and peace. Reconciliation is not only related to reconciling with others but also with self. Feeling guilt about the disease was considered a factor of feeling uncomfortable and grieving:

"Maybe I'm responsible for my illness, so I have to deal with it. If I am responsible, I have to pay for it. [pause] And I have to learn to live with it."(P4)

Peace is seen as a final state of well-being, based on simple things like feeling well with others:

"Comfort for me is to be at peace with everyone.’(P6)

Search for meaning Comfort, particularly with severe illness, was deemed an experience of personal growth, rediscovery of the meaning of life and appreciation of the really important: "In fact, I hope to keep the meaning of my life in love and connections with people. (...) Seeing this situation not only as a bad situation...(...) This needs to have a positive result. " (P10) 
Spiritual distress The participants' narratives show a comparison between spiritual and physical pain. While physical pain was considered easier to control, spiritual pain remains:

"Pain can go away. It hurts, but we call, they come here, and it is gone half an hour later. (...) But this [laying his hand to his chest, rubbing it, and look sad] ... This pain does not disappear. [Hand gesture in chest]" (P1)

\subsubsection{Me and the world around me}

This category comprises environmental factors and their influence on patient comfort. The place of care provision and its characteristics emerged as an important category for achieving comfort.

Place of care provision Participants referred home as the best place to be. It is a cozy place, where there are no rules, where they feel free, where they can be with their loved ones, and is also a place of personal identification. At home, they don't feel an object, a disease or a number but a person who belongs somewhere and to someone. Although home is considered the best place to be, participants reported that in hospital they get the clinical conditions they need at that moment. In a paradoxical way, hospital is seen as a place that limits their freedom but, simultaneously, offers safety and accepts human suffering.

"If I don't feel confident with being at home, I prefer being in the hospital and then, later, return home. Here, with the nurses, I'm fine ... (... ) I believe in them and I feel safe.”(P6)

The negative factors affecting patients' comfort during their hospitalization were the lack of materials, human resources and physical conditions. One of the most uncomfortable physical conditions specified in patient narratives is the presence of several patients in a ward and the lack of privacy and limited space.

"The space is small... [pause] And the conditions... The conditions here are not so good ... [pause]" (P9)

Silence is another important factor. The noise caused by other patients, by healthcare professionals in their routines, or even by alarms and monitors are considered causes of discomfort:

"Sometimes I want to rest but I can't. There is always someone who comes to the bell, there is always a machine alarm, there is a patient coughing ..." (P3)
The hospital is also described as a place that threatens the sense of freedom. Participants highlighted among the negative aspects, feeling locked behind closed doors, impossibility of going out to get some air, being restricted to the rules of the institution and living with other patients in the same ward (often neglecting their own needs and desires).

"Here, I have to comply with a general regime. I will not open a window just because I want to open a window. We have to think of the others. And I'm not going to create rules. Of course, if I was in my house and I wanted to open a window, I would open the window.'(P5)

\section{Discussion}

Comfort is basilar to palliative care. ${ }^{[1,2]}$ Nevertheless, there are many questions about the concept, its definition, implementation, measurement and evaluation remaining unclear. $^{[23]}$ These theoretical difficulties might have important implications in clinical practice and seems important to understand the meaning of comfort, in order to design, implement and evaluate feasible and effective interventions, centered on patients' experiences and expectations. ${ }^{[6,7,18,24]}$

The first aim of this study concerns PC patients' experiences on comfort. Despite patients have been invited to talk about a comfortable and uncomfortable experience, the great majority reported uncomfortable experiences. However, and as reported in previous studies, comfort experience is frequently explored and understood through discomfort experiences or in the absence of comfort. ${ }^{[25-27]}$

In this study, participants' experiences and views about comfort were represented in five main topics, regarding the physical, psychological, spiritual, social and environmental contexts. Findings highlight that participants experienced not only physical symptoms ("Me and what I feel") - such as pain, difficulty in resting, anorexia, asthenia and constipation - but also psychological ("Me and how I react") and spiritual problems ("Me and the meaning of my life"), such as lack of security, fear, sense of vulnerability, uncertainty, guilt and hopelessness. Expressing gratitude, enhancing hope, promoting reconciliation, searching for meaning in life, loving and being loved, and having the presence of a significant person emerged as important key activities to promote comfort. Illness is seen as a life condition that can increase spiritual growth and promote the journey of searching for the meaning of life, which is described as the main attribute of spirituality. ${ }^{[28]}$ When looking at the nurses' records is possible to realize the missing information when comparing to what patients' have been expressed.

The narratives have also described several dimensions re- 
lated to personal characteristics and to environmental context as well. Patients felt that hospital is a safe place and, at the same time, threatens the sense of freedom ("Me and the world around me"). Also, comforting depends on different actors such as the self (for example in the self-control, searching for meaning in life or expressing gratitude), the different healthcare team members (for example in symptom management), or the relatives (through their presence or forgiving the patient when he needs). At the same time, comforting appears as an individual and very subjective intervention, dependent of patient's characteristics, clinical condition, clinical setting, and family support ("Me a human being in society"). These results have been reported in other research, but not based on patients' perspective from a qualitative study. The results highlight the experience of in-patients and add consistency to the evidence reported in other contexts and countries. ${ }^{[6,27,29,30]}$ Thus, results give a comprehensive overview of comfort attributes throughout the perspective of palliative care patients, and open new perspectives to the operationalization of the comfort intervention.

Physical problems ("Me and what I feel") seem to have more impact on the psychological dimension ("Me and how I react") and, thus, on holistic comfort. Results showed that being physically dependent, for example, could increase the sense of vulnerability, which makes the person feel even more uncomfortable. The sense of vulnerability caused by disability and dependence plays an important role in patient self-control, as reported by other authors in previous research. ${ }^{[31,32]}$ Comfort is perceived as a holistic experience, and psycho-spiritual dimension is connected to physical, sociocultural and, also, environmental factors.

A second aim of this study is to contribute to the development of the nursing diagnosis "Impaired Comfort" (00214) listed in NANDA-I. ${ }^{[13]}$ The results highlight several patients' comfort needs that match the defining characteristics of this nursing diagnosis (see Figure 1).

When looking at the taxonomy II of NANDA-I, ${ }^{[13]}$ the nursing diagnosis "Impaired Comfort" (00214) includes the psychospiritual dimension in its definition. But the domain comfort excludes this attribute and is just comprising the classes related to physical, environmental and social dimensions of comfort. This study is bringing more evidence on the holistic and complex nature of comfort, as the changes that occurred in a given dimension (e.g., sleep disturbance) can be caused by several factors (such as pain, nursing routines or noise), and can result in different outcomes (for example, tiredness or irritation) (see Figure 1). This is quite important to nurse's clinical reasoning because if a patient is diagnosed with "Impaired Comfort" (00214) the nursing

Published by Sciedu Press interventions should be specific to the etiological factor or situation. The interventions towards the diagnosis "Impaired Comfort" (00214) may be similar to other nursing diagnosis such as "Hopelessness" (00124), "Spiritual Distress" (00066) or "Pain", which should be addressed at the same time. This is underlining the idea of "Impaired Comfort" (00214) not as problem-focused diagnosis, but as a syndrome, specifically for adults and older adults - "Impaired Comfort Syndrome in Adult and Older Adult". Understanding the meaning of comfort for hospitalized patients was helpful in clarifying the complexity and nature of the concept. At the same time, this study adds a contribution to the nursing knowledge in PC, documenting met and unmet needs of cancer and noncancer patients in acute care settings, which is very common in Latin countries.

Nevertheless, findings bridge the gap between previous knowledge and further research. In one hand, results are consistent with Kolcaba's Comfort Theory, ${ }^{[4]}$ supporting that comfort is not restrict to the physical dimension. On the other hand, the majority of comfort needs identified within each category have a correspondent nursing diagnosis at NANDA-I (see Figure 1). ${ }^{[13]}$ However, and as described before, patient's needs cannot be addressed independently, since they are frequently correlated, which lead to support the idea of "Impaired Comfort" as a syndrome diagnosis. ${ }^{[14]}$ Lastly, findings highlight that the environment plays an important role in the holistic comfort of the patient. However nursing diagnosis related to the environmental context are not present in NANDA-I (although the class exists). ${ }^{[13]}$

\section{Conclusions}

Comfort seems to be a human response that integrates several diagnoses, for which nurses should provide different but also similar and simultaneous interventions that are specific to the etiological factor (which is also a diagnosis). For this reason, we propose a new syndrome diagnosis. The study also provides a general overview of the main situations of discomfort of hospitalized patients suffering from chronic and incurable diseases. Agonizing symptoms are widely known as discomforting experiences. However, data emphasizes the importance of other determinants, such as the context of provision of care, the presence of family and significant others during the illness journey, the need to love and be loved, the way information is managed, the search for meaning of life and the need to continue to have control of life until the end. However, more studies are needed, with larger samples and in other contexts, such as home care or PC units. Whenever possible, multiple interviews over time are preferred to assess patient's experiences throughout their illness journey. Thus, caution is need when analyzing the results because 
some limitations are recognized, mostly cultural. Firstly, it was very difficult to recruit patients for the study because the vast majority were referred to $\mathrm{PC}$ in the agonic phase. When considering patients' comfort experiences over their illness journey, multiple interviews are usually the best way to do this, instead of single interviews at one point of time. However, the late referencing of PC patients to specialized teams/ services is a major barrier for recruitment of samples and for research purposes involving patients in Portugal, due to the rapid decline of their health status. Nevertheless, data saturation may have been limited by the clinical diagnosis of the participants. Indeed, the comfort perceived by a patient with heart disease, for example, may not be the same as a patient with AIDS, not only physically, but also regarding the psycho-spiritual and social dimensions.

Despite these limitations, the study provides a broad and useful overview about in-patient's experiences in acute settings,

\section{REFERENCES}

[1] Close JF, Long CO. Delirium: Opportunity for comfort in Palliative Care. J Hosp Palliat Nurs. 2012; 14(6): 386-394. https: //doi.org/10.1097/NJH.0b013e318262f5ba

[2] van der Steen JT, Radbruch L, Hertogh CM, et al. European Association for Palliative Care (EAPC). White paper defining optimal palliative care in older people with dementia: A Delphi study and recommendations from the European Association for Palliative Care. Palliat Med. 2014; 28(3): 197-209. https ://doi.org/10.1177/ 0269216313493685

[3] Sepúlveda C, Marlin A, Yoshida T, et al. Palliative Care: The World Health Organization's global perspective. J Pain Symptom Manage. 2002; 24(2): 91-96. https://doi.org/10.1016/S0885-3 924(02) 00440-2

[4] Kolcaba K. Comfort Theory and Practice: A vision for holistic health care and research. Ottawa: Springer Publishing Company; 2003. 263p. PMid: 12658237

[5] Pinto S, Caldeira S, Martins JC, et al. Evolutionary analysis of the concept of Comfort. Holist Nurs Pract. forthcoming 2017.

[6] Sousa P, Costa M. O cuidado confortador ao idoso crónico hospitalizado. Int J Develop Educ Psychol. 2012; 1(3): 347-355.

[7] Oliveira CS. Experiência de Confortar a Pessoa Hospitalizada: Uma abordagem fenomenológica. Pensar Enf. 2008; 12(1): 2-13.

[8] Xavier S, Pereira M, Canais E, et al. Comfort in patients with no chance of cure: What does it mean? J Nurs UFPE on line. 2013; 7(6): 4479-4487.

[9] Lin C. Comfort: A Value Forgotten in Nursing. Cancer Nurs. 2010; 33(6): 409-410.

[10] Pinto S, Caldeira S, Martins JC. Comfort in Palliative Care: Development and Evaluation of a Complex Intervention - Abstracts of the 8th World Research Congress of the European Association for Palliative Care (EAPC). Palliat Med. 2014; 28(6): 538-913. https://doi.org/10.1177/0269216314532748 which may be a first step to understand the complexity of the concept and the best way to achieve a feasible diagnosis and intervention regarding all patients with PC needs. Nevertheless, the study open new perspectives and creates an opportunity for further discussion about the meaning of concepts and nursing diagnoses, as well as the completeness and adequacy of the taxonomy structure, considering its translation to clinical practice. The present reflection was based on comfort, but other areas and domains of nursing knowledge within the classifications may and should be discussed, in order to provide scientific contributions to the improvement of classifications and to furthering nursing knowledge. These results add a particular contribution to the development of more feasible, personalized and effective nursing interventions.

\section{CONFlicts OF INTEREST Disclosure}

The authors declare that they have no competing interests.
[11] Pinto S, Caldeira S, Martins JC. A systematic literature review toward the characterization of comfort. Holist Nurs Pract. 2016; 30(1): 14-24. https://doi .org/10.1097/HNP.0000000000000126

[12] International Council of Nurses. ICNP Browser [Internet]. International Council of Nurses; 2015 [updated 2015; cited November 22]. Available from: http://www.icn.ch/ICNP-Browser-NEW.htm

[13] Herdman TH, Kamitsuru S (eds.). NANDA International Nursing Diagnoses: Definitions \& Classification, 2015-2017.10th ed. Oxford: Wiley Blackwell; 513p.

[14] Pinto S, Caldeira S, Martins JC. Is Impaired Comfort a Nursing Diagnosis? Int J Nurs Knowl. 2016; 27(4): 205-209. https: //doi.org/10.1111/2047-3095.12121

[15] Gysels M, Evans C, Higginson I. Patient, Caregiver, Health Professional and Researcher views and experiences of participating in research at the End of Life: A critical interpretive synthesis of the literature. BMC Med Res Methodol. 2012; 12: 123. https: //doi.org/10.1186/1471-2288-12-123

[16] Streubert H, Carpenter D. Investigação qualitativa em enfermagem: Avançando o imperativo humanista. 5th ed. Loures: Lusodidacta; 2013. 474p.

[17] Polit D, Beck C. Essentials of Nursing Research: Appraising evidence for Nursing Practice. 8th ed. Philadelphia: Wolters Kluwer Lippincot Williams \& Wilkins; 2014. 493p

[18] Kalyani MN, Kashkooli RI, Molazem Z, et al. Qualitative Inquiry into the Patients' Expectations regarding nurses and nursing care. Adv Nurs. 2014; Article ID 647653: 6 pages. https ://doi.org/ $10.1155 / 2014 / 647653$

[19] Kieft RA, de Brouwer BB, Francke AL, et al. How nurses and their work environment affect patient experiences of the quality of care: A qualitative study. BMC Health Serv Res. 2014; 14: 249. https://doi.org/10.1186/1472-6963-14-249

[20] Bos-Touwen I, Dijkkamp E, Kars M, et al. Potential for SelfManagement in Chronic Care: Nurses' Assessments of Patients. 
Nurs Res. 2015; 64(4): 282-290. https://doi.org/10.1097/NN R. 0000000000000103

[21] Tong A, Sainsbury P, Craig J. Consolidated criteria for reporting qualitative research (COREQ): A 32-item checklist for interviews and focus groups. Int J Qual Health Care. 2007; 19(6): 349-357. https://doi.org/10.1093/intqhc/mzm042

[22] Elo S, Kyngäs $H$. The qualitative content analysis process. J Adv Nurs. 2008; 62(1) : 107-115. https://doi.org/10.1111/j.13 $65-2648.2007 .04569 . x$

[23] Blinderman CD, Billings JA. Comfort Care for Patients Dying in the Hospital. N Engl J Med. 2015; 373(26): 2549-2561. https: //doi.org/10.1056/NEJMra1411746

[24] Roche-Fahy V, Dowling M. Providing comfort to patients in their palliative care trajectory: Experiences of female nurses working in an acute setting. Int J Palliat Nurs. 2009; 15(3): 134-141. https: //doi.org/10.12968/ijpn.2009.15.3.41092

[25] Kolcaba K, Kolcaba R. An analysis of the concept of comfort. J Adv Nurs. 1991; 16(11): 1301-1310. https://doi.org/10.1111/j. 1365-2648.1991.tb01558.x

[26] Kalfon P, Mimoz O, Auquier P, et al. Development and validation of a questionnaire for quantitative assessment of perceived discomforts in critically ill patients. Intensive Care Med. 2010; 36 (10) : 1751-1758. https://doi.org/10.1007/s00134-010-1902-9

[27] Coelho A, Parola V, Escobar-Bravo M, et al. Comfort experience in palliative care: A phenomenological study. BMC Palliat Care. 2016; 15: 71. https://doi.org/10.1186/s12904-016-0145-0

[28] Weathers E, McCarthy G, Coffey A. Concept Analysis of Spirituality: An Evolutionary Approach. Nurs Forum. 2016; 51(2): 79-96. https://doi.org/10.1111/nuf.12128

[29] Yousefi H, Abedi HA, Yarmohammadian MH, et al. Comfort as a basic need in hospitalized patients in Iran: a hermeneutic phenomenology study. J Adv Nurs. 2009; 65(9): 1891-1898. https: //doi.org/10.1111/j.1365-2648.2009.05026.x

[30] Waldrop DP, Kirkendall AM. Comfort measures: A qualitative study of nursing home-based end-of-life care. J Palliat Med. 2009; 12(8): 719-724. https://doi.org/10.1089/jpm.2009.0053

[31] Brenes GA, Penninx BW, Judd PH, et al. Anxiety, depression and disability across the lifespan. Aging Ment Health. 2008; 12(1): 158-163. https://doi.org/10.1080/13607860601124115

[32] Izumi S, Baggs JG, Knafl KA. Quality nursing care for hospitalized patients with advanced illness: Concept development. Res Nurs Health. 2010; 33(4): 299-315. https ://doi.org/10.1002/nur. 20391 